\title{
23 Conclusion
}

\section{Linde Egberts and Meindert Schroor}

Beginning in the 1960 s, it was environmentalists who put the Wadden Sea and its Frisian or Wadden Islands on the map. Since then, the Wadden Sea area has been defined both by its natural habitat and the area beyond the dikes, ultimately leading in 2009 to the designation of the Wadden Sea proper and its islands, or parts thereof, by UNESCO as a World Heritage Site. As such, the outstanding universal value of the Wadden Sea is derived from exclusively ecological and geological definitions, the area being 'the largest unbroken system of intertidal sand and mud flats in the world, with natural processes undisturbed throughout most of it' (UNESCO 2017). In recent years, though, researchers and policymakers have becomee increasingly aware that the Wadden Sea area is not only the Wadden Sea and the islands but also the mainland, particularly the clay areas or marshes extending from Den Helder in the Netherlands to Esbjerg in Denmark. Of course, this has always been where you can hear, see and feel the Wadden Sea: the screeching seagulls, the wide horizon, the unceasing salty sea wind tearing into the trees surrounding the farms and sometimes even into the very shell-permeated clay soils.

This volume emerged from the Waddenland Outstanding symposium held in Husum in December 2016 with the goal of firmly imprinting the Waddenland on the mental map of the Wadden Sea area. The symposium's central theme was the de facto neglect of this 'continental' part of the Wadden Sea area and the need to incorporate this geographical component. It treated, perhaps for the first time, existing and impending challenges for the whole of the Wadden Sea region - the sea, the islands and the mainland - intractable issues like climate change, economic decline in parts of the mainland versus gentrification on the islands, agricultural uncertainties, an aging population, and the perspectives and vicissitudes of tourism. The outcomes of the symposium led to the preparation of this book, to which it lends its name.

With this ambition and scope, this volume sets out to widen the knowledge about the Wadden Sea area to include its landside, both in geographical as well as in epistemological terms. Pushing forward beyond existing cultural historical research in this area (Fischer 1997), the volume aims to challenge the narrow definitions and borders of the Wadden Sea area, which are currently the dominant paradigm in research and are firmly entrenched 
in regional, national and international policy. Taking a different tack, it suggests new ways to perceive and manage the area when it comes to the preservation of natural and cultural historical values as well as coastal management.

This landscape of salt marshes that slowly developed in and around the shallow coastal Wadden Sea has been inhabited for some two-and-a-half millennia and been embanked since 1,00o AD. From that time, the land within the dikes went its own way: former gullies became ditches and canals, salt water was turned into fresh water, villages and towns developed, and the area and its people mentally moved away from the sea. And in recent decades, the protection of nature came to prevail over treasuring the human presence of the past and present.

This volume makes clear that, as a result, dualism has become one of the main characteristics of the Wadden Sea region. It is a dualism of many aspects - nature versus culture, sea versus land, islands versus mainland, salt water versus fresh water, protection versus development - but it is a dualism that needs to be overcome, if only in respect of the previously defined environmental challenges and the need for sustainable strategies in dealing with them. Several contributions stress the importance of a greater involvement of the inhabitants, not only on the islands but also on the mainland, the Waddenland which, after defining it from geographical, historical and cultural heritage perspectives, this volume discusses along four thematic lines. The first explains the origins of a deep-seated mental gap between nature and culture in the Western world in general and the Wadden Sea area in particular. One of the principal ways to overcome this gap is to listen more intensively to local populations and their unique perceptions of their surroundings, so frequently overlooked by politicians, researchers and civil servants, and to involve them in the process. Doing this means taking into account immaterial and intangible, often elusive but no less important values, recorded and expressed in myths and ideologies. These sometimes include certain aspects of Frisian history currently being used (and, some might say, misused) for cultural historical tourism, even as many other phenomena, such as the link between the component parts of the area through coastal trading or the widespread practice of winter-storage of excess water inside the dikes, seem to have faded from collective memory. This volume also underscores that history and archaeology can not only kindle interest but also offer depth in matters of nature management and viable spatial and economic planning, as well as provide a narrative useful to the development of responsible forms of cultural tourism. 
This volume ends with the different ways in which cultural heritage is and can be managed against the background of existing and future economic, social and political challenges. The conclusion is that a combination of old and forgotten practices and highly innovative, even provocative research, always integrating natural and cultural qualities of the Wadden Sea region, is essential. With this rich collection of contributions, we have tried to offer a compendium of recent research in the broad field of cultural history on the Wadden Sea area and to set out lines for future coastal management that will take a more integrative approach to natural and cultural values.

This volume illustrates that research on the history, cultural landscape and cultural heritage of the Waddenland has made great advances in the last decade. But there is still much to bebe done. A key issue will be the development of research that is: (1) programmatic, (2) interdisciplinary, (3) comparative, (4) long-term, and (5) participatory, with a perspective on developments over centuries (or millennia), coupled with historical and ethnographical detail. In this regard, we should applaud the initiative as formulated by the Dutch Waddenacademie to develop a trilateral research agenda (6). There is just one element to add: research should remain critical and be partisan where needed. How to navigate between a critical and a partisan position is, however, perhaps the most difficult question an individual researcher faces, especially in an area that has so many involved stakeholders (some of them in conflict).

Like any publication that is ambitious in its scope, the integrative strengths of this book come alongside several shortcomings and challenges it does not succeed in addressing. First of all, the focus of the contributions in the book is on the Wadden Sea area itself, with the consequence that the comparison with and position with respect to comparable areas is lacking. Based on the Essex Report (2010), Frederiksen (2012) made an interesting start towards positioning the cultural landscape among other wetlands with similar characteristics worldwide. Further analysis and comparisons could lead to insights that could be of great value not only for academic reflection but for management as well. Although the current volume contributes to the knowledge of the Wadden Sea region itself, it leaves the positioning of the area in a wider context to future publications.

The editors come to a similar conclusion with regard to the integration of the perspective of old and new inhabitants as well as visitors to the Wadden Sea area. Some of the contributions highlight the former and present inhabitants of the region while largely overlooking the modern visitor. As region branding and the sustainable development of tourism are rising in 
importance on the agendas of politicians in the region, it becomes increasingly important to better understand the meanings the region conveys to visitors from both near and far. In particular, an understanding of their appreciation of cultural heritage and landscape is needed, as these are being increasingly appropriated to draw visitors to the mainland of the Wadden Sea region. This implies the introduction of a contemporary economic dimension and cooperation with economists.

Although this volume was long-awaited and necessary, it still leaves several major ambitions for the future. While this book can be seen as an attempt to offer an integrative counternarrative to dominant nature conservation discourses, it does not go so far as to take the side of nature conservationists, ecologists and geologists. But its content does aim to trigger interest among natural scientists for the human aspects of the Wadden environment in which their work and aspirations unfold. A task for the near future would be to experiment with research projects, reflections and case studies that approach the interrelated natural and cultural qualities of the Wadden Sea region as mutually reinforcing.

\section{References}

Essex County Council Historic Environment Branch (2010). Comparative Analysis of the Landscape and Cultural Heritage of the Wadden Sea region. Chelmsford: Essex County Council.

Fischer, L. (1997). Kulturlandschaft Nordseemarschen (Nordfriisk instituut, nr. 129). Bräist/Bredstedt: Nordfriisk Instituut.

Frederiksen, J. (2012). The Wadden Sea Region. A World Class Cultural Landscape. Leeuwarden/Wilhelmshaven: Waddenacademie/Common Wadden Sea Secretariat (CWSS).

UNESCO (2017). Wadden Sea. Retrieved 24 December 2017 from http://whc.unesco. org/en/list/1314

\section{About the authors}

Dr. Linde Egberts is an assistant professor in the interdisciplinary field of heritage studies at Vrije Universiteit Amsterdam. She studied human geography and cultural history at Utrecht University and Vrije Universiteit Amsterdam, where she defended her PhD thesis, Chosen Legacies, in 2015. Her research interests lie in heritage, identity, regions, landscape, and the 
interplay of tourism and identity. As a member of the research institute CLUE+, she currently focuses on heritage in coastal landscapes in Europe. She combines her research endeavours with lecturing and coordinating the master's programme in heritage studies at Vrije Universiteit Amsterdam.

Dr. Meindert Schroor is a freelance geographer and historian at his own Bureau Varenius in Leeuwarden. Active since 1976 in researching and writing on the landscape, urban history, demography, water management and cartography of Fryslân (Friesland) and Groningen, he has developed into the most prolific researcher and writer on cultural history in the Northern Netherlands. Schroor received his PhD in 2014 on the demographic and economic history of the town of Groningen and is editor-in-chief of the New Encyclopaedia of Fryslân (published on paper in 2016). Since 2014, he has been a member of the board of the Waddenacademie responsible for the cultural history and society portfolio. 
